\title{
METABOLIC DISORDERS AND RENAL STONE
}

\author{
By A. R. HaRrison, M.D., M.R.C.P. \\ Institute of Urology
}

\section{Introduction}

Research into the aetiology of calculus disease has failed to reveal the fundamental cause of stone formation, but it is apparent that various factors predispose to their development. Renal calculi are likely to occur in most diseases in which there is an increased urinary excretion of crystalloid stone-forming substances. Calcium phosphate and oxalate stones are particularly liable to arise in disorders leading to hypercalcuria such as hyperparathyroidism, cystine calculi seem only to occur in those patients with cystinuria who excrete large amounts of this amino-acid, and there is some evidence that diseases causing a raised excretion of uric acid predispose to uric acid stones.

In this short review an attempt will be made to present the main diagnostic features of some of these diseases, particularly those in which patients may first seek advice because of symptoms of stone in the upper urinary tract.

\section{Increased Urinary Excretion of Calcium Normal Values}

Precise figures cannot be given, for even when allowances are made for age, body-weight and dietary intake, there seems to be a considerable variation in urinary calcium output among healthy individuals (Knapp, 1947). However, when no attempt is made to standardize diets, healthy adults rarely excrete more than $300 \mathrm{mg}$. per day, and when low calcium diets are taken the limit of output is about $150 \mathrm{mg}$. per day.

\section{Disorders Causing Hypercalcuria}

Hypercalcuria will occur in any condition in which calcium is lost from the skeleton, e.g. hyperparathyroidism, diseases causing local destruction of bone such as osteolytic metastases and multiple myelomatosis, and the various forms of osteoporosis including those due to immobilization and Cushing's syndrome.

In these the raised urine calcium reflects the transfer of calcium from the skeleton into the body fluids, but in vitamin $D$ intoxication and possibly in some cases of sarcoidosis (Anderson, Harper, Dent and Philpott, 1954) there is increased alimentary absorption of calcium.

In various forms of acidosis, including renal tubular acidosis and that which may follow uretero-sigmoidostomy, excessive calcium is excreted with other bases of the body.

Finally, in idiopathic hypercalcuria it is possible that there is diminished renal tubular reabsorptive capacity for calcium.

\section{Hyperparathyroidism}

Many descriptions of this disorder, such as that of Albright and Reifenstein (1948), have been published and only a brief account of the clinical features need be given here. Skeletal symptoms range from solitary swellings to the generalized bone pains, deformities, multiple swellings and pathological fractures of osteitis fibrosa cystica. Renal calculi and nephrocalcinosis are common, as is some degree of renal failure. Indeed, in severe cases with extensive nephrocalcinosis, renal failure may be irreversible and progressive even after parathyroidectomy. Hypercalcaemia itself may give rise to muscular hypotonicity and weakness, anorexia and constipation.

As this disorder was first recognized by its effects on the skeleton, it was inevitable that cases with skeletal lesions predominated in early reports. However, Albright and his colleagues, in a series of papers (1934, 1937, 1948), demonstrated that renal calculi and nephrocalcinosis are more frequent consequences of hyperparathyroidism than skeletal lesions. Widespread recognition of this was slow to develop, but it has now been abundantly confirmed. Norris (1947) in a review of the $3^{1} 4$ cases then published showed that only 17 of these had renal lesions alone, and in ror there were renal and skeletal lesions. Pyrah and Raper (1955) stated that of 266 cases published after 1947,136 had renal lesions alone and a further 66 had renal and skeletal lesions.

In the past 18 motiths the diagnosis has been made in I I patients admitted to our metabolic ward. In eight of these the diagnosis has been 
confirmed at operation, but the remaining three still await surgical exploration. In these hospitals there will obviously be a bias towards cases with stone or nephrocalcinosis, but in none of the ro patients who displayed such lesions was there any evidence of bone disease. The remaining patient had osteitis fibrosa cystica and no renal lesion.

\section{Diagnosis}

When osteitis fibrosa cystica is present, diagnosis is not difficult, but it is evident that many patients with hyperparathyroidism will present at urological clinics as cases of calculus disease. In these, diagnosis is not easy, for clinical and routine examinations of the urinary tract will not distinguish them from other patients with calcium phosphate or calcium oxalate stones. Hyperparathyroidism is more likely when stones are bilateral or recurrent or when nephrocalcinosis is present, but none of these features is pathognomonic of the disease, and all may be absent in its early stages. The diagnosis can only be established by biochemical investigations.

\section{Biochemical Features}

The mode of action of parathormone may still be controversial, but there is no disagreement regarding the biochemical changes it produces; elevation of the plasma calcium, lowering of the plasma inorganic phosphate (phosphorus) and increases in the urinary excretion of calcium and phosphorus.

Plasma Calcium.-The normal range is 9- $\mathrm{I} \mathrm{mg} . /$ roo $\mathrm{ml}$. In hyperparathyroidism values vary from those which are obviously high, e.g. 16 or $17 \mathrm{mg}$./ $100 \mathrm{ml}$., to those which are only slightly elevated. In one of our confirmed cases, who had normal plasma proteins, the highest reading obtained was I $1.4 \mathrm{mg}$./ $100 \mathrm{ml}$ : and the average of four readings was II.I mg./100 ml. Laboratory techniques cannot be discussed here, but if such cases are to be diagnosed a consistently high standard of accuracy in assays is essential. Since part of the calcium is bound to proteir, hypoproteinaemia may mask hypercalcaemia and, therefore, plasma proteins should always be estimated. Conversely, the total plasma calcium may rise because of hyperproteinaemia. Occlusion of the arm veins, particularly if combined with repeated clenching of the hand, may occasionally lead to local concentration of the plasma protein and its bound calcium and, therefore, it is advisable to withdraw blood samples without using a tourniquet.

Plasma Phosphorus. - The average normal value is $3.5 \mathrm{mg}$./ roo ml., but in health there may be appreciable fluctuations throughout the day and estimations should preferably be made on fasting blood specimens. The values obtained in this

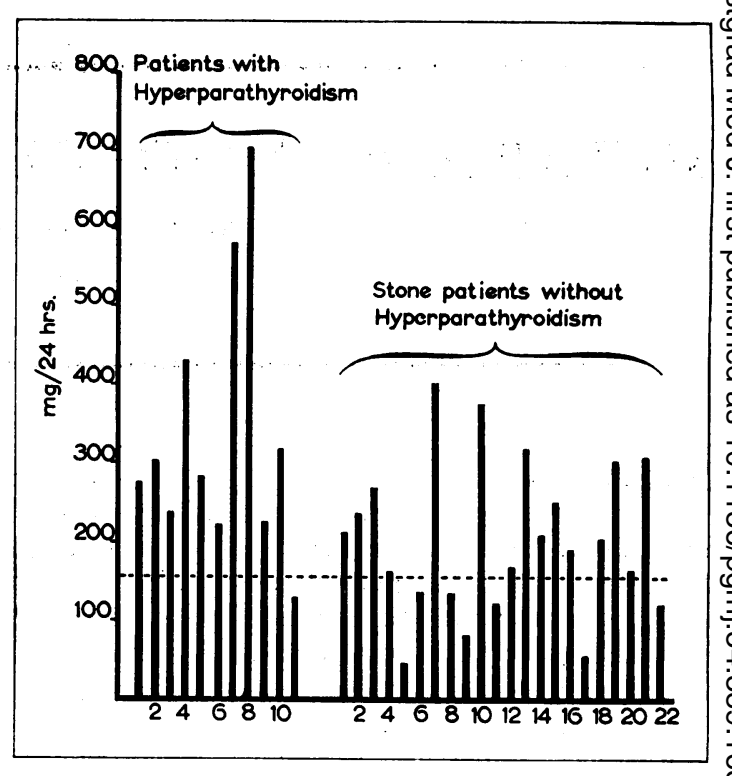

FIG. 1.-Daily urinary calcium output in 33 patients on a low calcium intake. Note that 15 of the $22 \mathrm{~S}$ patients without hyperparathyroidism exhibit hyper- calcuria (more than $150 \mathrm{mg}$. per day).

disease vary from those which are obviously lowz e.g. $2.0 \mathrm{mg}$./ $100 \mathrm{ml}$., or less, to those which do nơ differ much from low 'normals,' e.g. $3.0 \mathrm{mg}$ $100 \mathrm{ml}$. If renal failure is present an increase renal clearance of phosphate cannot occur and the plasma level will not fall.

Plasma Alkaline Phosphatase.-It is only in patients with bone lesions that the alkaline phosphatase is raised beyond the normal range $(3-\mathrm{I} 3$ King-Armstrong units).

Urinary Calcium Output.-An increased urinary calcium excretion is not pathognomonic of hyperparathyroidism, for in other disorders there may be hypercalcuria even when calcium intake is low (Fig. I). On the other hand, if the urine calcium is low then hyperparathyroidism is virtually excluded.

The Sulkowitch test provides a rough but quick method of estimating the urinary calcium content and when the extremes of reaction are encountered is of value for screening purposes. A faint precipitate in a concentrated urine specimen denotes $N$ a low calcium content, and makes hyperpara- $N$ thyroidism unlikely, whereas a heavy precipitate in a dilute specimen calls for more precise investigations. More information can be achieved by estimating the calcium in $24-\mathrm{hr}$. urine specimens. When the patient is taking a normal diet, levels of over $300 \mathrm{mg}$. are suspiciously high. When estimations are made after the patient has been 0 taking, a neutral-ash low-calcium diet for five or 
six days, values of $150 \mathrm{mg} . / 24 \mathrm{hr}$. are suspiciously high and of $200 \mathrm{mg}$. or more abnormal. This test, although elaborate, is of value in mild cases when the blood changes are only slight.

Urinary Phosphate Output.--Since this fluctuates appreciably with variation in dietary intake, estimations are rarely utilized in diagnosis. Nordin and Fraser (1956) evolved a test which relates the urinary phosphate output to plasma phosphate levels and the renal clearance of creatinine; a high phosphate/creatinine clearance ratio being found in hyperparathyroidism. This procedure may be of help in doubtful cases, though McGeown and Bull (1957) found it of only limited value.

It must be appreciated that the diagnosis of hyperparathyroidism may not be easy. No single laboratory investigation will provide absolute. proof of the diagnosis, which can only be established after careful interpretation of a number of investigations which may need to be performed repeatedly.

\section{Treatment}

Surgical removal of the adenoma is the only successful form of treatment.

\section{Differential Diagnosis}

Occasionally nephrocalcinosis and lithiasis associated with hypercalcaemia and hypercalcuria occur in sarcoidosis (Longcope and Freiman, 1952). Confusion with hyperparathyroidism is possible, but the plasma phosphorus is not low; other signs of sarcoidosis may be present, and if doubt still exists cortisone may be administered, for this reduces the hypercalcaemia in sarcoid (Anderson et al., 1954).

Osteolytic metastases and multiple myelomatosis can cause extensive destruction of bone, with an outpouring of calcium. When this is rapid the plasma as well as the urine calcium may rise and the picture mimic hyperparathyroidism.

\section{Renal Tubular Acidosis}

A disorder characterized by hyperchloraemic acidosis and nephrocalcinosis may first become apparent in infancy, adolescence or adult life. In I936 Butler, Wilson and Farber described the infantile form, in I940 Albright, Consolazio, Coombs, Sulkowitch and Talbott reported a similar condition in an adolescent girl who presented with rickets and dwarfism, and in 1945 Baines, Barclay and Cooke described it in an adult who presented with renal colic.

Although the infantile type differs in its course from that appearing in later life the essential metabolic disturbance appears to be the same in each. Following the pioneer work of Albright et al. (1940) it is now believed that the disorder is due to inability of the kidney tubules to manufacture ammonia and to acidify the urine by the formation of free $\mathrm{H}^{+}$ions. Other renal functions, e.g. the excretion of urea, remain relatively intact. As a result of this tubular defect, excess base, notably potassium and calcium, is lost in the renal excretion of acid metabolites, and low potassium syndromes and osteomalacia may arise. Furthermore, the high urinary calcium output and the continual neutrality of the urine favour the precipitation of calcium salts within the kidney and urinary tract, so producing nephrocalcinosis or, less commonly, calculi.

Laboratory investigations show a low plasma $\mathrm{CO}_{2}$-combining power, a high chloride and, unless there has been secondary renal damage, a normal blood urea. Plasma calcium is normal or low, and the phosphorus low; the alkaline phosphatase is raised if there is osteomalacia. The diagnosis is established by demonstrating the patient's inability to excrete an acid urine after the administration of ammonium chloride.

It is important to recognize this condition, for further renal calcification and stone formation may be prevented by the regular administration of alkaline salts such as sodium bicarbonate or citrate.

\section{Idiopathic Hypercalcuria}

Flocks (1939) found a high urinary calcium output in a large proportion of his patients with calcium-containing renal stones. None of these patients had a raised plasma calcium or any demonstrable metabolic abnormality which could account for the increased urinary calcium. Similar findings have been reported by others (Sutherland, 1954; Pyrah and Raper, 1955; Cottet and Vittu, 1955) and it would seem that a large number of such cases are revealed whenever urinary calcium estimations are performed as a routine investigation in stone patients.

Fig. 2a shows the readings obtained in our own metabolic department on a consecutive series of stone patients who did not appear to be suffering from metabolic disorders such as hyperparathyroidism. If allowance is made for the inclusion of patients with renal failure, whose urinary calcium is low, it will be seen that over 50 per cent. excrete more than $300 \mathrm{mg}$. calcium per day. The available evidence suggests that only a small proportion of normal individuals excrete such an amount, and it was exceeded only once in our few healthy controls. (Fig. 2b.)

The mechanism of this disorder is unknown, but the association of a high urinary calcium output with normal blood levels suggests a diminished capacity of the renal tubules to re- 

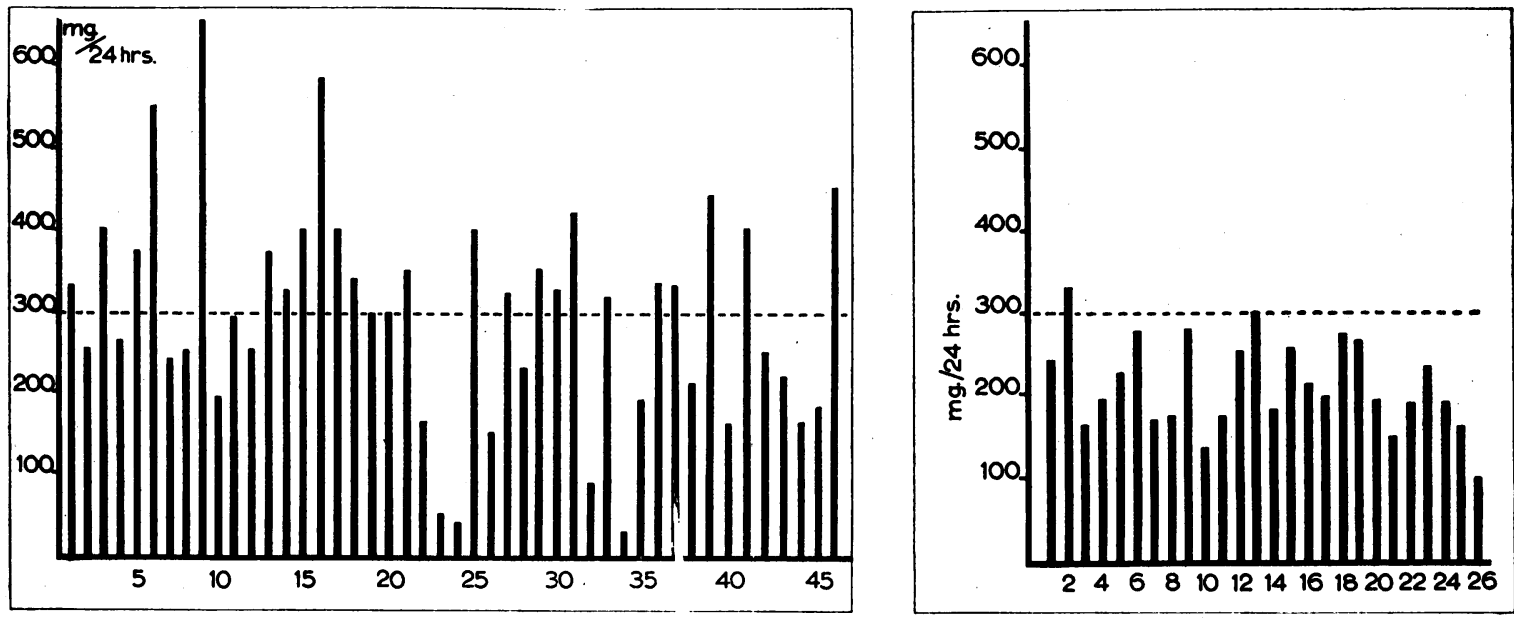

FIGS. 2A and 2B.-Daily urinary calcium output in 46 stone patients on normal diets (2A) contrasted with 26 healthy controls (2B). None of the 46 patients had hyperparathyroidism. Cases $23,24,32$ and 34 had renal failure.

absorb calcium from the glomerular filtrate. If an abnormal urinary calcium loss is the only abnormality, then at least some patients with this disorder should be in a state of negative total calcium balance and eventually develop osteomalacia. Yet although the condition is common in patients with stone, osteomalacia is not. Possibly there is an increased absorption of dietary calcium which compensates for the high urinary loss, but it seems unlikely that overabsorption of dietary calcium is the primary dysfunction for, even when calcium intake is low, the urinary output is still abnormally high (Fig. I).

The distinction between this condition and hyperparathyroidism may be very difficult and depends entirely on the blood chemistry-particularly on the blood calcium levels.

No satisfactory treatment is available. Reduction of calcium intake will diminish the urinary output in some of these cases, but this measure may induce a negative total calcium balance with all its attendant dangers. Maintenance of a water diuresis will reduce the concentration of calcium in the urine, and this, perhaps, is the only form of therapy that can be freely advised.

\section{Cystinuria}

Normally the urine contains only small quantities of cystine, but it has long been recognized that certain individuals, often members of the same family, excrete markedly excessive quantities of this sulphur-containing amino-acid and that some of them form cystine stones.

Until recently this disorder was thought to be due to an inborn error, or block, in the metabolism of cystine, which, therefore, accumulated in the body fluids and spilled over into the urine. However, Dent and his colleagues investigated this disorder with new chemical methods, notably paper chromatography, and have shown that the defect lies in the renal tubules (Dent, I949; Dent and Rose, 195I; Dent et al., 1954a, b). The tubules are unable to reabsorb cystine and certain other amino-acids from the glomerular filtrate These other amino-acids are lysine and, in severes grades of the disorder, arginine and ornithine.

There is considerable variation in the amounts of cystine excreted by different individuals with this disorder, variation which can perhaps be explained on a genetic basis. Genetical studies (Harris and Warren, r953; Harris, Mittwoch, Robson and Warren, r955) suggest that the disorder is inherited as a Mendelian recessive characteristic and that those individuals who inherit two abnormal genes, i.e. the recessive homozygotes, excrete the greatest amounts of cystine and also the three other amino-acids. Those who are heterozygous either are normal or excrete smaller quantities of cystine and lysine only.

These studies have also thrown light on the problem of calculus formation, for it would appear that stones only form in individuals excreting large quantities of cystine, i.e. the homozygotes. Indeed, the work of Dent and Senior (1955) suggests that stones only form when the urine is supersaturated with cystine and, furthermore, that when supersaturation is present the incidence of calculi is very high.

The diagnosis is suggested when there is a history of bilateral recurrent calculi, often beginning at an early age, or when there is a 年 $\overrightarrow{0}$ . 


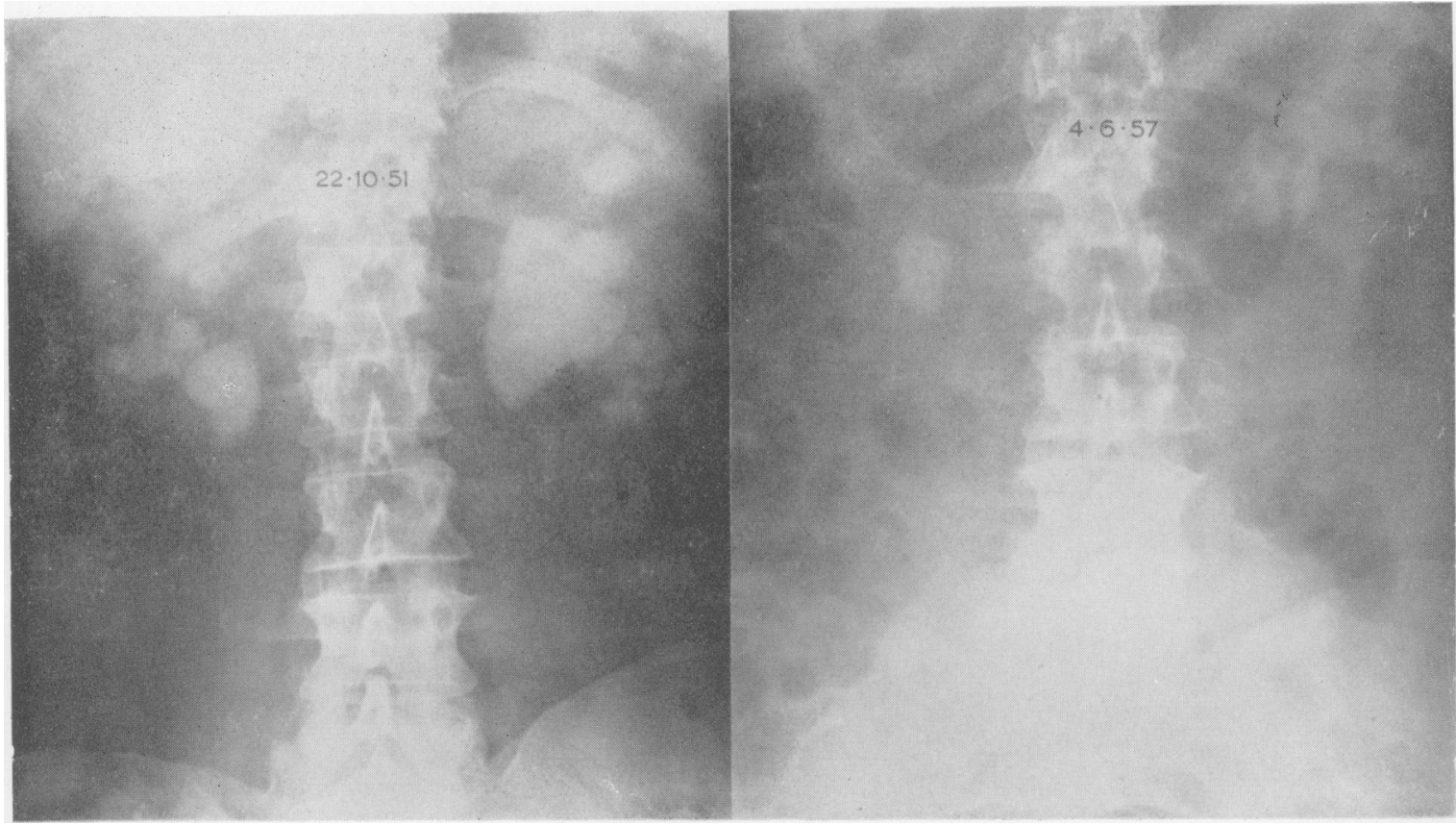

FIG. 3.- Spontaneous change in plain $\mathrm{X}$-ray appearances in a patient with cystine calculi who developed renal failure. (a) October i $95 \mathrm{I}$ : Blood urea $68 \mathrm{mg}$. per $100 \mathrm{ml}$

(b) June I957: Blood urea $120 \mathrm{mg}$. per $100 \mathrm{ml}$.

history of calculus formation in siblings. All but the smallest cystine stones are radio-opaque, though their density to X-rays is less than that of calcium-containing stones. Large staghorn calculi may form, as well as multiple small stones, and not infrequently they occur together. When there is no stone available for analysis, cystine can be detected in the urine by the simple cyanidenitroprusside test of Brand, Harris and Biloon (1930).

\section{Treatment}

Dent and Senior, arguing from their simple theory of the pathogenesis of stones in cystinuria, suggest that further calculus formation will be prevented, and existing stones perhaps dissolve, if the urine can be kept undersaturated with cystine. Cystine output cannot be reduced, but undersaturation can be achieved if the urine volume is maintained at over 31 . per day by means of an increased water intake. It is, of course, necessary to obtain the secretion of a dilute urine by night as well as by day, and this requires that the patient cooperate by drinking about $\mathrm{I}$ pt. of water on retiring. In our own patients the preliminary results of this treatment are encouraging, but follow-up periods are too short for any final assessment to be made.

As pointed out by Dent and Senior, this concept of calculus formation and treatment is favoured by the observation that stones may diminish in size once renal failure supervenes, for then not only will less cystine be excreted by the glomeruli but, in addition, the kidney will be unable to form a concentrated urine. This was seen in one of our patients (Fig. 3).

In addition to a high-fluid intake, urinary alkalinizing agents may be given, for cystine is more soluble in alkaline solutions.

It is generally believed that causal metabolic factors will be found in only a small proportion of patients with nephrolithiasis and, if idiopathic hypercalcuria is excluded, this is probably true. Nevertheless, the incidence of such factors might well prove higher if biochemical investigations were invariably part of routine urological examination. It must be admitted that the more elaborate biochemical tests are time consuming and may call for the facilities of a large laboratory or even a metabolic ward, but much information can be gained from those which are well within the scope of any general hospital with adequate laboratory facilities.

Plasma calcium and phosphorus determinations should always be carried out in patients with calcium-containing stones; the cyanide-nitroprusside test for cystine can be performed in a few 
minutes in the out-patient department, and even urine calcium estimations are not too difficult to organize.

\section{BIBLIOGRAPHY}

ALBRIGH'T, F., BAIRD, P. C., COPE, O., and BLOOMBERG, E. (1934), Amer. F. med. Sci., 187, 49 .

ALBRIGHT, F., CONSOLAZIO, W. V., COOMBs, F. s., SULKOWITCH, H. W., and 'TALBOTT, J. H.' (I940), Bull. Fohns Hopk. Hosp., 66, 7.

ALBRIGHT, F., and REIFENSTEIN, E. C. (1948), 'The Parathyroid Glands and Metabolic Bone Disease,' London: Baillière, Tindall and Cox.

AI.BRIGH T, F., SULKOWITCH, H. W., and BLOOMBER(; E. (1937), Amer. F. med. Sci., 193, 8 10.

ANDERSON, J., DENT, C. E., HARPER, C., and PHILPO'TT, G. R. (1954), Lancet, ii, 720 .

BAINES, C. H., BARCLAY, J. A., and COOKE, W. 'T. (1945), Quart. F. Med., 14, I I3.

BRAND, E., HARRIS, M. M., and BILOON, S. (1930), f. biol. Chem., 86, 3 I 5 .

BUTLER, A. M., WILSON, J. L., and FARBER, S. (1936), 7. Paediat., 8, 489 .
COTTET, J., and VITTU, C. (1955), Presse méd., 63, 878.

DENT, C. E. (1949), Symp. Biochem. Soc., No. 3, 34

DENT, C. E., HEA'THCOTE, J. G., and JORON, (j.E. (195+a), f. clin. Invest., 33, 1210.

DENT, C. E., and ROSE, G. A. (1951), Quart. F. Med., 20, 205. DENT, C. E., and SENIOR, B. (1955), Brit. f. Urol., 27, 317

DENT, C. E., SENIOR, B., and WALSHE, J. M. (1954b), f. clin. Invest., 33, 1216 .

FLOCKS, R. H. (1939), f. Amer. med. Ass., 113, 1466.

HARRIS, H. MITTWOCH, U ROBSON, E. B., and WARREN, F. L. (1955), Ann. Human Genetics, 19, 196.

HARRIS, H., and WARREN, F. L. (I953), Ann. Eugen. (Camb.), I8, 125 .

KNAPP, E. L. (1947), f. clin. Invest., 26, 182.

LONGCOPE, W., and FREIMAN, D. G. (1952), Medicine, 3I, I. MCGEOWN, M. G., and BULL, G. M. (1957), Brit. med. Bull., I3, 53

NORDIN, B. E. C., and FRASER, R. (1956), 'Ciba Foundation Symposium on Bone Structure and Metabolism,' London: Churchill.

NORRIS, E. H. (1947), Int. Abstr. Surg., 84, I.

PYRAH, L. N., and RAPER, F. P. (I955), Brit. F. Lirol., 27, 333. SUTHERLAND, J. W. (r954), Ibid., 26, 22.

UNIVERSITY OF GLASGOW AND ROYAL FACULTY OF PHYSICIANS AND SURGEONS POSTGRADUATE MEDICAL EDUCATION COMMITTEE

\section{CONFERENCE TN NEDPLANIA}

A specialist conference on Neoplasia will be held in the Royal Faculty of Physicians and Surgeons, 242 St. Vincent Street, Glasgow, C.2, from the 26th to the 28th of March, 1958. The conference is open to all medical pract.tioners. The programme is as follows:

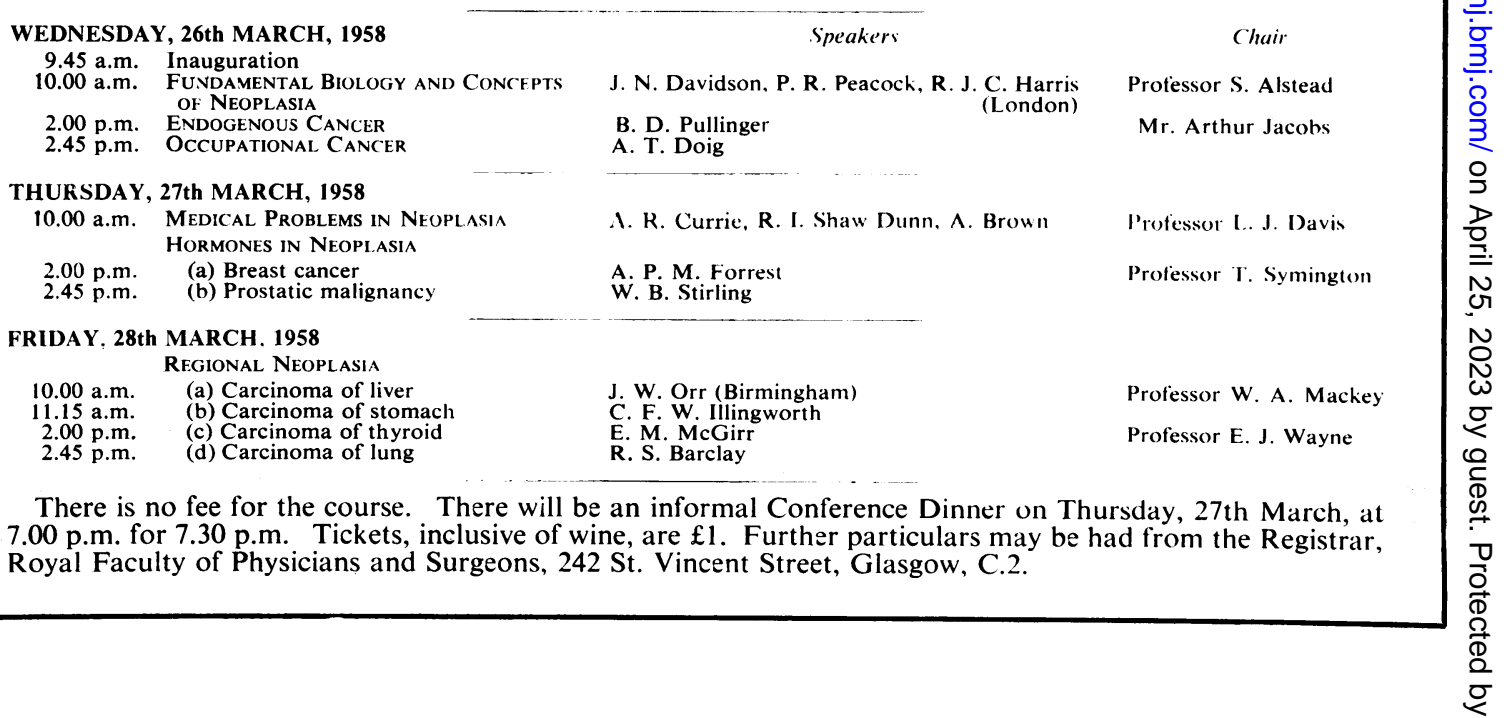

